\title{
Educação Financeira no ensino médio: relações com a Matemática Financeira na prática docente
}

Danilo Pontual de Melo

Cristiane Azevêdo dos Santos Pessoa

\section{Resumo}

Neste artigo apresentamos um recorte de um estudo de mestrado. Discutimos o ensino da Educação Financeira (EF) durante as aulas de Matemática Financeira (MF) no Ensino Médio. Com a facilidade de acesso ao crédito e as altas taxas de juros é importante que as pessoas sejam educadas financeiramente, no entanto, defendemos que a EF deve envolver discussões para além de questões como pagar à vista ou parcelado. Utilizamos como aporte teórico a Educação Matemática Crítica de Skovsmose (2000). Nosso objetivo é analisar a abordagem da EF por professores do Ensino Médio durante aulas de MF. Usamos atividades de MF que apresentem potencial para discussão sobre EF, selecionadas do livro didático adotado pelos professores pesquisados. Relacionamos as orientações presentes no manual do professor e a prática em sala. Verificamos também as relações estabelecidas entre os conteúdos de MF e a $\mathrm{EF}$. Concluímos que o trabalho com a EF envolve elementos que vão além da prática docente, é preciso que tenhamos uma formação de professores numa perspectiva crítica de EF e que as orientações presentes no manual não abordem as situações financeiras apenas para identificar a melhor forma de pagamento ou em qual situação hipotética de empréstimo vamos pagar menos juros, deixando de lado as questões sociais, políticas, culturais, éticas e ambientais que permeiam as discussões da EF.

Palavras-Chave: Educação Financeira, Educação Matemática Crítica, Matemática Financeira, Prática docente. 


\title{
Financial education in high school: relations with Financial Mathematics in teaching practice
}

\author{
Danilo Pontual de Melo \\ Cristiane Azevêdo dos Santos Pessoa
}

\section{Abstract}

In this paper we present a fragment of a broader study which is part of a master's degree. We discuss the teaching of Financial Education (FE) within the lessons of Financial Mathematics (FM) in high school. With easier access to credit and the high interest rates it is of great importance that people are financially educated, nevertheless, we advocate that FE should embrace discussions beyond matters such as paying on demand or by installments. We have used as theoretical support the Critical Mathematics Education by Skovsmose (2000). Our aim is to analyze the approach of FE by teachers of High School during lessons of FM. We have used exercises of FM which present potential for discussion over FE, selected from the textbook adopted by the studied teachers. We have related the orientations presented in the teacher's guide and the practice within the class. We have also verified the relations established amongst the contents of FM and FE. We have concluded that the work with FE involves elements which go beyond the teaching practice, it is necessary that we have a teaching training in a critical perspective of $\mathrm{FE}$ and that the orientations in the teacher's guide do not approach the financial situations simply to identify the best payment method or in which hypothetical situation of loan we shall pay less interest, leaving aside the social, political, cultural, ethical and environmental matters which pervade the discussions of FE.

Keywords: Financial Education, Critical Mathematics Education, Financial Mathematics, Teaching practice. 


\section{Introdução}

No presente artigo apresentamos um recorte de um estudo maior, de mestrado, no qual pretendemos discutir como acontece e quais as possibilidades de abordagem da Educação Financeira (EF) durante aulas de Matemática, sobretudo o, de Matemática Financeira (MF).

Por se tratar de uma discussão recente, principalmente do ponto de vista da formação educacional, a EF não é trabalhada explicitamente nos currículos escolares do país. Algumas escolas privadas desenvolvem projetos nesta área, por meio de empresas privadas que oferecem materiais, mas no que confere às escolas públicas, na grande maioria não acontece um trabalho estruturado com a temática.

A EF é colocada em prática através da Estratégia Nacional de Educação Financeira (ENEF), adotada como política de Estado de caráter permanente para a promoção de ações de EF no país, por meio do Decreto Federal 7.397/2010. Segundo a ENEF, seu objetivo é de contribuir para o fortalecimento da cidadania e assim ajudar as pessoas na tomada de decisões financeiras autônomas e conscientes. Esta estratégia é resultado da articulação entre governo, sociedade civil e iniciativa privada, no entanto, como já destacamos, essa política precisa ser colocada em prática em todas as escolas, para que tenhamos uma formação sólida em Educação Financeira.

Diante desse cenário, refletimos aqui acerca de algumas possibilidades para a abordagem da $\mathrm{EF}$, isso não quer dizer que iremos apontar uma fórmula para tratar desta nas escolas, mas sim, defender que juntos possamos construir um trabalho com a EF pautada em uma formação cultural, social, política, econômica, ambiental, ética, entre outros valores que nós, como sociedade, estamos tão necessitados.

Vamos discutir a EF a partir das aproximações e relações que podemos construir com a MF, mas podemos abordar a temática de forma interdisciplinar. Optamos pelas aulas de Matemática Financeira para articulação entre os conteúdos matemáticos e as discussões de situações financeiras, pois no currículo escolar é a área mais próxima da temática do nosso estudo e isso permite o registro da possibilidade de abordagem, mesmo quando os currículos não estabelecem esse trabalho de forma clara.

A EF deve ser abordada a partir de um olhar crítico e reflexivo. Na medida em que estabelecemos essa postura, aproximamo-nos das preocupações estabelecidas por Skovsmose (2000) em sua Educação Matemática Crítica (EMC), quando o autor busca discutir o papel social, político e econômico da Matemática, transformando-a dessa forma em uma ferramenta de investigação e estímulo à autonomia intelectual. $\mathrm{O}$ autor busca estabelecer as preocupações da EMC, a partir da ideia de que uma atividade realizada em sala de aula pode permitir aos estudantes o estabelecimento de uma relação entre a discussão que a atividade 
possibilita e suas respectivas vivências sociais. A partir desses aspectos presentes na construção teórica da EMC, realizamos uma relação com o que entendemos por uma EF em uma perspectiva crítica.

Dentre as várias discussões que a EMC apresenta, realizamos um recorte para os ambientes de aprendizagem presentes nas aulas de Matemática. Para Skovsmose (2000), um dos principais desafios da Educação Matemática é proporcionar aos alunos uma aprendizagem que tenha mais sentido como alternativa ao ensino da Matemática pautado em fórmulas e memorizações, surgem os cenários para investigação que, diferentemente da bateria de exercícios, as trilhas dos cenários para investigação são mais reflexivas e construtivas. Os cenários para investigação e os exercícios estabelecem diferentes ambientes de aprendizagem, que se diferem de acordo com as referências feitas pelos alunos e pelo professor quando estão engajados nas atividades. Podem ser feitas referências a conceitos puramente matemáticos, a objetos que parecem vir da realidade e podem ainda fazer referência a situações da vida real. É a combinação dos três tipos de referências com os dois paradigmas de ensino que sala de aula se estabelece uma matriz de ambientes de aprendizagem, que detalhamos a seguir em nossa fundamentação teórica.

Nossa problemática de pesquisa consiste em discutir a EF e as diversas possibilidades de abordagem da temática em aulas de Matemática Financeira no Ensino Médio, pela necessidade de compreendermos as práticas apresentadas por professores no trabalho em sala de aula e também identificar potenciais que permitam uma abordagem crítica da Educação Financeira apresentados por esses docentes na organização das suas aulas. Para tanto, pretendemos também discutir como as preocupações da Educação Matemática Crítica podem auxiliar nesse processo da prática em sala de aula, através dos ambientes de aprendizagem propostos por Skovsmose (2000).

Nosso objetivo geral é analisar a abordagem da EF por professores do Ensino Médio durante aulas de Matemática Financeira. Apresentamos aqui os resultados apenas de uma professora participante por se tratar da apresentação de resultados de um estudo-piloto, serão discutidos apenas os resultados da aula de uma professora. Buscamos inicialmente identificar o perfil profissional e os conhecimentos da professora sobre EF. Utilizamos o livro didático adotado pela professora, para seleção das atividades abordadas na aula, analisando os ambientes de aprendizagem presentes nas atividades. Relacionamos as orientações presentes no manual do professor para as atividades propostas e a prática da professora. Apresentamos o roteiro elaborado pela professora com a observação da prática em sala de aula, destacando as aproximações e relações estabelecidas entre os conteúdos de MF e a EF, além de discutir como acontecem na prática de sala de aula os ambientes de aprendizagem propostos por Skovsmose (2000).

ISSN 2526-2882

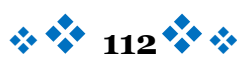


Nas próximas seções apresentamos as discussões que permeiam a EF, assim como as preocupações e perspectivas da EMC acerca do ensino da Matemática, bem como nossos resultados e considerações parciais do estudo em andamento.

\section{Educação Financeira}

A Educação Financeira (EF) está cada dia ganhando mais espaço nas discussões que envolvem nossa vida em sociedade, principalmente em um momento em que o acesso ao crédito e às facilidades das compras parceladas está cada vez mais se difundindo no comércio. Encontramos várias empresas "preocupadas" em educar financeiramente a população, mas será que é realmente do interesse delas que as pessoas sejam críticas em relação ao uso do dinheiro?

Apesar da crise política e financeira que o nosso país vive atualmente, hoje as pessoas possuem maior acesso ao crédito, se compararmos a épocas anteriores. Esse pode ser um fator positivo, mas que se a população não possuir um conhecimento financeiro, pode gerar um consumo desenfreado, causando o comprometimento da renda familiar a curto, médio e longo prazo. Coutinho e Teixeira (2015) destacam que esse consumo deve acontecer de forma planejada, de modo que analisemos essa facilidade de crédito que encontramos, pois ela pode implicar no acúmulo de dívidas e descontrole da vida financeira.

A perspectiva da EF adotada por bancos e instituições financeiras busca o poupar hoje para gastar em um futuro a curto, médio ou longo prazo, dependendo do bem que se pretende adquirir, incentivando, de certa forma, o consumismo. Bauman (2008) afirma que consumo é "uma condição, e um aspecto, permanente e irremovível, sem limites temporais ou históricos; um elemento inesperável da sobrevivência biológica que nós humanos compartilhamos com todos os outros organismos vivos" (BAUMAN, 2008, p.37). Entretanto, este teórico afirma que consumo é diferente de consumismo e este segundo ocorre com os excessos, ou seja, quando se compra por impulso ou quando se compra mais do que se precisa, quando se compra por desejo e não por necessidade. Assim, o consumismo pode ser fruto de "ataques" da mídia, das propagandas, do marketing, que investem para criar nas pessoas necessidades que, na verdade, são desejos. Ainda em relação ao consumismo, Bauman (2008) afirma que

“...podemos dizer que o 'consumismo' é um tipo de arranjo social resultante da reciclagem de vontades, desejos e anseios humanos rotineiros, permanentes e, por assim dizer, "neutros quanto ao regime", transformandose na principal força propulsora e operativa da sociedade" (BAUMAN, 2008, p.41). 
A discussão da Educação Financeira, como já destacado, é um tema presente e pertinente na sociedade em que estamos vivendo atualmente. Estamos constantemente diante de situações que necessitam de uma tomada de decisão econômica. Santos e Pessoa (2016) ressaltam que a discussão sobre EF no Brasil é algo recente e, portanto, por ser um tema novo é necessário que ele seja pensado e investigado.

$\mathrm{Na}$ sociedade de consumo em que estamos inseridos e que passa por mudanças constantes em sua estrutura econômica, social, política e cultural, as pessoas são cada vez mais estimuladas a praticar o consumismo, colocando o planejamento familiar a médio e longo prazo em risco. Ganha, portanto, espaço na sociedade, nas escolas e na academia a discussão que envolve a importância da EF para reflexões acerca de questões de consumo, ética, influência da mídia, sustentabilidade entre outros.

Diante da importância da temática, um número cada vez maior de professores e pesquisadores vem defendendo a inserção da EF nas escolas. Silva e Powell (2015) apontam em seus estudos recomendações de que devemos iniciar o trabalho com a EF desde cedo nas escolas, considerando o fato de que quanto mais cedo as pessoas forem educadas financeiramente, melhores relações terão com estas questões ao longo da vida. Essa abordagem deve ir além de aprender a economizar, cortar gastos, juntar dinheiro, ela deve envolver a reflexão e a compreensão de habilidades e conhecimentos acerca de consumo, ética, influência da mídia, preservação do meio ambiente, valor dos produtos, entre outras questões presentes na nossa vida em sociedade.

Santos (2016) destaca algumas temáticas relevantes que devemos abordar na sala de aula quando tratamos de uma abordagem crítica e reflexiva da EF. Segundo a autora, devemos discutir:

Situações de compra e venda com discussões sobre consumo consciente, querer versus precisar, pesquisa de preços, qualidade $\mathrm{x}$ preço, dentre outros que ajudem em reflexões acerca da EF. Além disso, destaca-se a importância de que temáticas como economia, poupança e importância de planejamento e de um controle de gastos sejam, também, discutidas com os alunos (SANTOS, 2016, p. 03).

Em relação ao conceito da EF na perspectiva escolar, assumimos aqui o proposto por Silva e Powell (2013). Os autores defendem que:

A Educação Financeira Escolar constitui-se de um conjunto de informações através do qual os estudantes são introduzidos no universo do dinheiro e estimulados a produzir uma compreensão sobre finanças e economia, através de um processo de ensino que os torne aptos a analisar, fazer julgamentos fundamentados, tomar decisões e ter posições críticas sobre questões financeiras que envolvam sua vida pessoal, familiar e da sociedade em que vivem (SILVA; POWELL, 2013, p. 12). 
A partir das discussões existentes sobre EF, o Grupo de Estudos e Desenvolvimento da Matemática na Educação Básica - Gredam - defende uma EF que facilite o desenvolvimento de reflexões críticas e proporcione aos alunos tomadas de decisões conscientes e uma aprendizagem mais contextualizada, tendo em vista que a Matemática, além de fazer parte da realidade, também pode ser capaz de nela intervir. Além do auxílio na administração do dinheiro, também é papel da EF propiciar a discussão acerca de um consumo consciente, da influência que a mídia exerce nas escolhas diárias, da reflexão sobre o que desejamos e o que realmente precisamos e sobre o impacto ambiental que algumas escolhas podem causar (PESSOA, 2016).

Encontramos aproximações entre as discussões de Bauman (2008) e o que defendemos como abordagem da EF escolar, em que os estudantes possam refletir sobre as armadilhas do consumismo, das criações falsas de necessidades (quando na verdade são desejos), da influência que a mídia, as propagandas e o marketing exercem em uma sociedade, da importância da preservação ambiental para a saúde do nosso planeta, dentre outras reflexões críticas.

Mesmo com a implementação da ENEF, acreditamos que a forma como a EF vem sendo abordada nas escolas ainda necessita de um processo de aprimoramento e adequação aos objetivos educacionais. Por se tratar de uma discussão recente, pode estar sendo abordada em sala de aula na mesma perspectiva da EF de bancos e instituições financeiras, em que os estudantes são conduzidos a um processo mecânico de resolução de cálculos financeiros, sem uma discussão crítica dos aspectos envolvidos.

Rosetti e Schimiguel (2009), ressaltam a importância da EF durante a educação básica e profissional, a partir dos Parâmetros Curriculares Nacionais (PCN, 1997) estabelecidos, diante das demandas que a sociedade nos apresenta. Os autores destacam ainda a dificuldade que o ensino da Matemática, em sua maioria, de proporcionar uma formação integral dos jovens. "Assim, o ensino e uso dos modelos matemáticos/financeiros em sala de aula devem estar em consonância com as necessidades, os interesses e as experiências de vida dos alunos" (ROSETTI; SCHIMIGUEL, 2009, p. 2). Estes autores defendem a implementação de competências e habilidades que proporcionem uma postura autônoma diante dos problemas a serem enfrentados.

Sobre a importância de se trabalhar a EF nas escolas, Campos (2013) destaca que todos nós, desde a infância, temos disponíveis diversos bens e serviços e essa vivência se torna ainda mais intensa quando se trata de jovens egressos da educação básica, que estão adentrando fortemente na administração de seus próprios orçamentos e estão diante de situações de tomada de decisão em relação ao seu próprio dinheiro. E como estímulo para o consumismo, o apelo do marketing se torna cada vez mais intenso a cada dia, por isso a 
importância que os estudantes tenham contanto com discussões de cunho financeiro desde cedo nas escolas.

Para Pessoa (2016), quanto mais a sociedade se complexifica, mais necessário é o domínio do conhecimento financeiro das pessoas de qualquer nível socioeconômico, que compõem a sociedade. Assim como apontado por Pessoa (2016), sobre a abordagem da EF e na relação direta que a temática possui com a realidade de modo que permite um trabalho mais significativo e relevante, Oliveira (2016) destaca que embora a EF seja recente na perspectiva escolar, sua presença contribui de forma eficiente para uma formação crítica dos estudantes.

\begin{abstract}
Embora seja uma temática nova, sua importância vem sendo ressaltada, pois frente a um contexto social permeado por demandas de consumo, por mudanças nas relações sociais e modos de vida, em uma sociedade cada vez mais complexa e que exige do cidadão conhecimentos referentes a como lidar com o dinheiro, possibilidades de escolhas, armadilhas do consumismo, tomadas de decisão, reflexões sobre os conceitos de querer e de precisar, usos de produtos financeiros de modo consciente, dentre outros, torna-se indispensável a inserção de um trabalho com a EF nas escolas (OLIVEIRA, 2016, p. 2).
\end{abstract}

Muniz (2016) elabora princípios que devemos considerar quando tratamos do trabalho com EF nas escolas. Para ele, devemos ter em mente que a EF deve oferecer aos estudantes oportunidade de reflexão, por meio de situações financeiras, para que eles possam vir a tomar suas próprias decisões. Há uma diferenciação da EF escolar da EF de bancos e outras instituições financeiras pois, diferente destas, a EF escolar está voltada para o ensino e a aprendizagem, sem deixar de considerar os fatores econômicos e sociais, já que estes estarão conectados às questões de ensino, e que além de ajudar na análise e tomada de decisão em situações financeiras, permitirá ao aluno explorar situações financeiras para compreender os conceitos matemáticos envolvidos, buscando oferecer múltiplas leituras sobre as situações financeiras através de uma lente multidisciplinar.

Silva (2015) destaca que nas definições de EF ainda há um discurso direcionado para conhecimentos administrativos e econômicos, daí a necessidade de se compreender melhor o papel da EF no contexto educacional. E mais, segundo a autora, o foco da EF nas escolas são as aulas de Matemática durante a abordagem da Matemática Financeira, no entanto defende a necessidade de uma abordagem mais ampla, já que a temática comtempla temas como os impactos sociais e ambientais causados pelo consumo inconsciente, por exemplo.

De fato, uma das dificuldades na abordagem da EF nas escolas é que muitas vezes ela é tratada como sinônimo da Matemática Financeira (MF). No entanto, entendemos que não são sinônimos, pois enquanto a primeira busca o desenvolvimento de uma postura crítica diante de situações financeiras, auxiliando na tomada de decisões, a MF busca trabalhar 
conceitos matemáticos para aplicação a dados financeiros em geral. Em sua tese de doutorado, Teixeira (2015) realizou um estudo com um grupo de cento e sessenta e um (161) professores que ministram aulas de Matemática no Ensino Médio, sobre as percepções da relação entre EF e MF e concluiu que a maioria dos professores desconhece essa diferença.

É importante registrar, no entanto, que não retiramos a importância da abordagem da MF, o que não é desejável é que fiquemos restritos apenas ao aprendizado e à aplicação de fórmulas, que não ajudam o sujeito no desenvolvimento de uma análise crítica na tomada de decisões. A MF deve sim, como ferramenta, auxiliar nesse processo de construção do conhecimento financeiro. É o que defende Gaban e Dias (2016, p. o9) quando afirma que “...ser educado financeiramente, ajuda o indivíduo na tomada de decisões, em seus planejamentos e, consequentemente, faz com que aprenda a lidar com suas finanças utilizando como principal ferramenta para isso a Matemática Financeira”.

Em relação à abordagem da EF durante as aulas de MF, Cunha e Laudares (2017) destacam que:

\begin{abstract}
Para a efetivação de Educação Financeira, há necessidade de uma transição no ensino da Matemática Financeira, para o exercício da reflexão e crítica acerca de situações que influenciam a vida financeira das pessoas, não se limitando à simples aplicação de fórmulas de juros simples ou compostos ou outros cálculos mais sofisticados (CUNHA; LAUDARES, 2017, p.4).
\end{abstract}

É importante que a discussão das situações financeiras durante as aulas de MF aconteça em uma perspectiva de uma formação crítica, preocupada com a formação integral do sujeito e as ações dele na sociedade. Neste sentido, concordamos com Lima e Sá (2010) quando defendem que

Ensinar matemática financeira para as crianças não é só ensiná-las a lidar com o dinheiro, mas sim fazer com que eles rejeitem a corrupção, façam negociações justas, cumpram prazos e valores combinados, tenham consciência ambiental usando sem desperdiçar os recursos naturais tendo um pensamento coletivo e humanitário e por fim que sejam responsáveis socialmente (LIMA; SÁ, 2010, p. 5).

Tratando ainda sobre as problemáticas desenvolvidas durante a abordagem da EF na escola, Santos e Pessoa (2016) apontam a existência de uma diversidade de compreensões por parte de pesquisadores da maneira como a abordagem deve acontecer. As autoras apontam a existência de um grupo de pesquisadores que defendem o desenvolvimento da EF a partir da MF, enquanto outros defendem uma abordagem transversal ao currículo de Matemática, de forma que permita contemplar outras áreas do conhecimento.

Os estudos apresentam como ponto de similitude a percepção de que a EF não se restringe à compreensão acerca de finanças pessoais ou ao hábito de ISSN 2526-2882

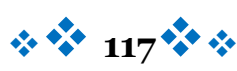


poupar para comprar algo no futuro, indo muito além em suas discussões, com temáticas tais como "querer x precisar", ética, consumismo, entre outros (SANTOS; PESSOA, 2016, p. 4).

Entendemos as compreensões apresentadas pelas autoras como complementares, pois ambas são importantes formas de abordagem para a EF na escola. Enquanto a defesa de que seja abordado a partir dos conteúdos da MF se mostra importante, pois possibilita uma abordagem mínima da EF durante aulas de MF, a vertente transversal se mostra forte, pois permite que a discussão sobre EF não esteja presente apenas nas aulas de MF, nem apenas nas aulas de Matemática, sendo possível também uma formação integral em relação às situações financeiras na nossa vida em sociedade.

No tópico a seguir apresentamos nossa fundamentação teórica, que nos permite uma análise crítica fundamentada da abordagem da EF durante as aulas de MF. Trata-se da Educação Matemática Crítica, organizada a partir das preocupações de Skovsmose (2000) acerca da Educação Matemática.

\section{Educação Matemática Crítica}

A Educação Matemática Crítica (EMC) busca discutir a Matemática a partir de uma perspectiva social, política, econômica, entre outros aspectos que permeiam nossa sociedade. A EMC objetiva a utilização da Matemática como ferramenta de investigação e estímulo à autonomia intelectual. Skovsmose é um dos maiores representantes da discussão acerca da EMC, na qual, segundo o autor, “...busco expressar certas preocupações a respeito da educação matemática” (SKOVSMOSE, 2014, p.10).

Da maneira como eu concebo a educação matemática crítica, ela não se reduz a uma subárea da educação matemática; assim como ela não se ocupa de metodologias e técnicas pedagógicas ou conteúdos programáticos. A educação matemática crítica é a expressão de preocupações a respeito da educação matemática (SKOVSMOSE, 2014, p.11).

A preocupação sobre a qual devemos estar atentos no campo da Educação Matemática diz respeito ao poder de despotencialização e potencialização dos alunos, consequência direta da forma como a Matemática é abordada durante as aulas. Segundo Skovsmose (2014) a Educação Matemática despotencializa os alunos quando não consideramos os aspectos sociopolíticos envolvidos. Os exercícios da Matemática tradicional são fortes representantes desse aspecto da Educação Matemática, essa prática, contudo não ajuda a desenvolver a criatividade matemática. Por outro lado, o autor destaca que a matemática produz alguma forma de potencialização dos alunos e destaca três formas: o 
desenvolvimento da inteligência, a maior chance de sucesso pessoal e o papel social da matemática.

Santos e Miranda (2016) destacam que quando falamos da formação para a cidadania, do posicionamento político e de uma postura crítica no interior das relações sociais, na maioria das vezes a Matemática, como ensinada hoje, aborda de forma superficial essas questões. É nesse sentido que a EMC pretende discutir e destacar o caráter sóciopolítico da Matemática.

Se realizarmos uma análise crítica dos modelos de aulas de Matemática que mais encontramos atualmente, podemos destacar inicialmente que em sua maioria são desenvolvidas a partir de um roteiro pré-estabelecido, que deve ser colocado em prática em sala de aula. Como consequência, os estudantes não compreendem o sentido do que estão estudando e as aulas acabam por reproduzir ambientes de desigualdades presentes na sociedade.

Diante dessa problemática em relação às aulas de Matemática, surge a necessidade do desenvolvimento de situações de investigação durante as aulas, em que a Matemática seja abordada em uma perspectiva crítica, em que os estudantes sejam colocados como sujeitos ativos no processo de aprendizagem. No entanto para que aconteça o desenvolvimento desse ambiente, deve ocorrer uma mudança na postura do professor. Bennemann e Allevato (2011) defendem que a relação entre professor e aluno deve ser necessariamente democrática, baseada no diálogo na intenção de interagir em situações sociais e políticas estruturadas pela Matemática.

Os professores, em sua maioria, não raramente vêm treinando os estudantes a resolverem exercícios-modelos, baseados na crença de que quanto maior o número de modelos dominados, maiores serão as chances de sucesso nas diversas avaliações escolares ou em outras, como concursos, por exemplo, que seguem essa linha de perguntas com exercícios-modelos (SKOVSMOSE, 2000). Para Bennemann e Allevato (2011) isso estimula a escola a permanecer com esse modelo de ensino que atende a uma demanda social. No entanto, o que encontramos são discursos da necessidade de criatividade, raciocínio lógico, capacidade de análise, entre outras habilidades, que possivelmente não serão atingidas ao trabalharmos apenas com os exercícios-modelos.

Segundo Skovsmose (2000) e as ideias da EMC, as aulas de Matemática estão situadas em dois paradigmas, o paradigma do exercício e o paradigma dos cenários para investigação. O primeiro diz respeito aos modelos de aulas que citamos anteriormente, em que são trabalhados prioritariamente aspectos mecânicos de repetição e memorização. Enquanto o segundo diz respeito a um trabalho de investigação durante as aulas, em que o professor faz um convite e os alunos aceitam vivenciar de forma ativa no processo de ISSN 2526-2882

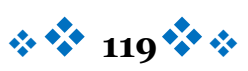


construção do conhecimento durante as aulas de Matemática. "Um cenário para investigação é aquele que convida os alunos a formularem questões e procurarem explicações" (SKOVSMOSE, 2000, p. 6).

O autor destaca ainda que a distinção entre as duas práticas de sala de aulas se diferem de acordo com a referência encontrada na abordagem das aulas. Podemos encontrar referências à matemática pura, à semirealidade, ou à realidade. E a combinação dos dois paradigmas com os três tipos de referências, segundo Skovsmose (2000) formam os ambientes de aprendizagem defendidos pela EMC, como podemos observar no Quadro 1.

\begin{tabular}{|c|c|c|}
\hline & Exercícios & Cenários para investigação \\
\hline Referências à matemática pura & (1) & (2) \\
\hline Referências à semirrealidade & (3) & (4) \\
\hline Referências à realidade & (5) & $(6)$ \\
\hline
\end{tabular}

Fonte: Adaptado de (SKOVSMOSE, 2000, p.8).

As atividades que fazem referência à matemática pura correspondem a questões que buscam apenas o trabalho com operações matemáticas, sem uma preocupação com a contextualização. Podemos entender semirealidade como uma realidade construída pelo autor de um livro didático, por exemplo, quando cria uma situação hipotética que serve apenas para ilustrar a situação com os dados da atividade, mas que podemos mudá-la para outra situação com os mesmos dados e o resultado continua sendo o mesmo. Já nas atividades situadas na realidade, os dados são reais e contribuem para a estruturação, entendimento e resolução do problema.

No ambiente do tipo (1) as atividades são muito comuns em aulas de Matemática pouco reflexivas e pouco exploram a criatividade, uma vez que neste tipo de ambiente, prevalece a mecanização dos procedimentos de resolução, bem como a ideia de que a aprendizagem se dá a partir da repetição de modelos.

As atividades do tipo (2) fazem referência à matemática pura, mas envolvem algum tipo de investigação, desafios a serem cumpridos, relações matemáticas a serem percebidas. Os alunos são incentivados a fazer aproximações, discutir hipóteses, argumentar, debater etc.

O ambiente do tipo (3) é composto por atividades desenvolvidas a partir de situações imaginárias, fictícias, construídas pelo autor da atividade, mas ainda está situada no paradigma do exercício, pois a situação não leva a uma discussão/problematização.

O ambiente do tipo (4) é caracterizado pela presença de atividades que fazem referência também a uma semirealidade, como o tipo (3), no entanto está relacionado aos cenários para investigação. No entanto ainda existe uma certa limitação nesse ambiente, 
pois mesmo em um processo de investigação, estamos situados em situação construída e não verificável.

Quando a atividade apresenta elementos da realidade, mas ainda é solicitada a realização de exercícios com esses dados, sem um direcionamento no sentido de investigação, dizemos que a atividade corresponde ao ambiente do tipo (5). Este ambiente é caracterizado pela presença de exercícios que fazem menção à vida real, como a utilização de gráficos com dados reais, por exemplo (SKOVSMOSE, 2014, p. 56).

Atividades em que os estudantes são levados a questionar, investigar, complementar informações, ir a campo, argumentar, vivenciar, por exemplo, são consideradas do tipo (6) e são construídas a partir de elementos provenientes da realidade.

Skovsmose (2000) defende, no entanto, que nenhum ambiente é mais importante que o outro, não devemos privilegiar um ambiente em detrimento do outro, mas que devemos transitar pelas diferentes possibilidades apresentadas no Quadro 1, dependendo dos objetivos das aulas, “...caminhar entre os diferentes ambientes de aprendizagem pode ser uma forma de engajar os alunos em ação e reflexão e, dessa maneira, dar à educação matemática uma dimensão crítica" (SKOVSMOSE, p.1, 2000). Ele defende, ainda, que muitas vezes, um ambiente se complementa de outro, que há intersecções entre os diferentes ambientes.

Concordamos com o autor sobre o papel social que podemos e devemos empregar às aulas de Matemática, quando enxergamos nelas esse potencial e não apenas como uma disciplina em que tratamos de cálculos puros, aplicações de fórmulas e, o mais comum, memorização sem o entendimento do que realmente se trata o conteúdo discutido. Ressaltando, claro, que não defendemos o fim dos cálculos e exercícios nas aulas de Matemática, mas que esses sejam utilizados com o propósito educacional ao qual correspondem e não como única saída para a abordagem dos conteúdos matemáticos.

Temos como objetivo geral analisar como acontece a abordagem da EF por uma professora de Matemática do Ensino Médio durante aulas de MF. De forma específica, objetivamos: 1) identificar o perfil profissional e os conhecimentos da professora sobre EF; 2) analisar os ambientes de aprendizagem presentes nas atividades de Matemática Financeira com potencial para discussão sobre Educação Financeira presentes no livro didático adotado pela professora; 3) relacionar as orientações do manual do professor para as atividades propostas e o roteiro elaborado pela professora com a prática em sala de aula; 4) verificar as relações estabelecidas entre os conteúdos de $\mathrm{MF}$ e a EF; 5) verificar como acontece na prática de sala de aula a abordagem dos ambientes de aprendizagem propostos por Skovsmose (2000). 


\section{Método}

Inicialmente realizamos uma entrevista para caracterização do perfil profissional da professora sobre EF, MF e suas possíveis relações. Para a seleção de atividades indicadas, analisamos o capítulo de MF do livro didático utilizado pela docente. Classificamos as atividades a partir dos ambientes de aprendizagem propostos por Skovsmose (2000), identificando o potencial de cada atividade ser desenvolvida em determinado ambiente, pois apenas a partir da prática da professora em sala de aula podemos determinar qual/quais ambientes de aprendizagem estão sendo desenvolvidos.

Durante a observação da prática sugerimos duas das atividades à professora com antecedência ao período de observação das aulas. No momento da entrega solicitamos a realização de um roteiro de aula em que as atividades estejam inseridas. A professora pode organizar diferentes formas de abordagem e não necessariamente utilizar apenas as atividades sugeridas.

Realizamos entrevista semiestruturada, cujos questionamentos são apresentados no quadro a seguir. A entrevista foi composta por dois blocos principais, o primeiro correspondeu ao perfil profissional, no segundo bloco buscamos identificar elementos presentes na relação entre EF e MF. Na seção seguinte apresentamos os resultados encontrados após a realização do percurso metodológico.

Quadro 2 - Roteiro da entrevista semiestruturada.

\begin{tabular}{|l|l|}
\hline \multicolumn{1}{|c|}{ Perfil profissional } & \multicolumn{1}{c|}{ Conhecimentos de EF e MF } \\
\hline Quanto tempo de experiência profissional? & $\begin{array}{l}\text { O que entende por Educação Financeira? Já possuiu } \\
\text { algum contato com a discussão acerca da EF? }\end{array}$ \\
\hline Possui algum curso de Pós-Graduação? & E o que entende por Matemática Financeira? \\
\hline Há quanto tempo trabalha na escola? & Identifica alguma relação entre as duas (EF e MF)? \\
\hline $\begin{array}{l}\text { Como organiza suas aulas? Elabora algum tipo de } \\
\text { roteiro de aula? }\end{array}$ & $\begin{array}{l}\text { Utiliza alguma estratégia didática para abordar a } \\
\text { questão dos conteúdos financeiros durante as aulas? }\end{array}$ \\
\hline
\end{tabular}

Fonte: Os autores.

\section{Resultados}

A seguir apresentamos os resultados do nosso estudo com a professora participante, os quais estão organizados de forma que ao final da apresentação e discussão dos mesmos, possamos problematizar a abordagem da EF e suas aproximações e relações com a MF.

\section{Características profissionais da professora participante e suas concepções sobre a relação existente entre $\mathrm{EF}$ e $\mathrm{MF}$}

Destacamos a seguir, características da professora participante. Ela possui oito anos de experiência profissional, há dois é professora da escola na qual realizamos a entrevista e observação, é técnica em contabilidade como formação inicial, depois de um período concluiu a graduação em Licenciatura em Matemática, com especialização em Metodologia no Ensino 
da Matemática e da Física. Tem interesse em dar continuidade aos estudos, cursando mestrado na área de Metodologia do Ensino.

Como estamos utilizando as atividades presentes no livro didático adotado pela professora, buscamos então compreender como acontece a utilização do livro didático em suas aulas e ela destaca que não restringe as aulas apenas a um livro, utiliza vários, conforme a necessidade e característica de cada um.

Sobre o contato com a MF durante a formação inicial, ela recorda que estudou apenas durante o curso técnico em Contabilidade, mas que durante a graduação não cursou nenhuma disciplina que aborda a temática. Mesmo sem possuir um contato acadêmico durante sua formação, interrogamos sobre sua concepção de MF e obtivemos a seguinte resposta:

\begin{abstract}
Matemática Financeira aproxima o cotidiano do aluno, ela traz aquilo que o aluno vê no dia a dia, porque o aluno quando passa na loja, ele vê ali, promoção, 50\% de desconto, ali tem Matemática Financeira, mas ele não faz essa relação, então quando a gente traz essa disciplina pra sala de aula, a gente tá buscando aquilo que ele já vê no dia a dia pra abordar em sala de aula, pra ele entender que aquilo também faz parte da Matemática, o lucro, o juro, né? Aquele desconto[...] (Professora, 2017).
\end{abstract}

A fala da professora mostra que para ela a MF é importante por aproximar o estudante de situações do seu dia a dia. No entanto, será que podemos afirmar que uma atividade de MF apenas por apresentar uma situação de compra à vista ou a prazo (para que o aluno apenas aplique as fórmulas estudadas e identifique a situação mais vantajosa de pagamento) é pertinente para a formação de um sujeito crítico do ponto de vista financeiro/social? Será que é possível a MF estabelecer essa relação com o cotidiano do aluno, por meio dos seus conceitos, como juro, lucro e desconto, dentre outros? Defendemos que a EF é o campo de discussão de questões que extrapolam a aplicação de valores préestabelecidos em fórmulas prontas apresentadas ao estudante, visando a possibilitar uma discussão mais ampla, não só do ponto de vista econômico (quando abordamos a MF), mas sim, político, cultural, ambiental, ético, entre outros possíveis.

Ela destaca a forte presença das fórmulas nos livros didáticos, o que coaduna com os resultados do estudo de Gaban e Dias (2016), no qual os autores destacam que em sua maioria, as atividades encontradas nas coleções do PNLD de 2015 que eles analisaram são classificadas como sendo exercícios na semirrealidade (SKOVSMOSE, 2000) e fazem referência a conteúdos técnicos da MF. Na análise realizada, os autores destacam a forte presença do paradigma do exercício. Segundo eles, em se tratando da MF os livros ainda trazem atividades em sua maioria que estão restritas a aplicação de conteúdos técnicos, sem possibilidades da construção de um cenário investigativo.

ISSN 2526-2882

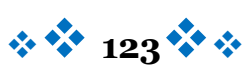


Procuramos compreender também qual a visão da professora sobre EF, com o objetivo de identificar se ela apresenta uma ideia distinta da apresentada sobre MF.

Não, não... [pensa mais um pouco] Na televisão, né? E nas redes sociais, você pode ver que a própria mídia, eles abordam muito essa Educação Financeira, que é com relação a todos os aspectos, agora eles quando abordam, eles levam muito pra doméstica, né? Mas de qualquer forma é Educação Financeira, como você administrar o seu salário, né? Eu acho que a mídia traz mais nesse sentido (Professora, 2017).

Como destacado pela própria, em sua fala anterior, a sua visão de EF ainda é muito ligada e restrita ao controle de despesas, como administrar o salário. Com o objetivo de despertar a ideia de que podemos ter também uma discussão sobre EF que aborda aspectos para além da administração doméstica do dinheiro, questionamos como ela acredita que podemos abordar a EF de outra forma, em uma perspectiva mais ampla.

Eu vejo mais nessa parte mesmo, a Educação Financeira doméstica, como controlar os gastos, né? Quanto você pode gastar de energia para não passar daquilo, quanto pode ser tua conta de água, quanto de cartão de crédito, quantas porcentagens do seu salário pode gastar com lazer, né? Mas isso tem que ser feito desde pequeno, porque quando você começa dando dinheiro ao filho você tem que orientar ele como utilizar aquele dinheiro, né? Quando você dá a mesada, ele saber que ele não pode chegar hoje e levar a mesada dele toda para a escola e consumir hoje, você tem que explicar para ele, que ele tem que consumir aquele dinheiro durante a semana, isso é uma Educação Financeira de qualquer forma, agora voltada para a parte doméstica, não é? (Professora, 2017).

Seguimos na discussão sobre a abordagem recebida pela EF nas escolas. Apresentamos como alternativa a relação da EF com as discussões ambientais, em relação à fabricação dos produtos. A professora acha importante que a abordagem aconteça dessa forma, mas destaca que nunca pensou a EF nessa perspectiva, e reconhece que sempre aborda a EF com situações “mais próximas” dos alunos.

É interessante perceber que a entrevista serviu como um momento de reflexão para a professora, pois a partir das nossas intervenções e ilustrações de possíveis abordagens da EF direcionadas a partir de suas respostas aos questionamentos, é possível identificar que sua compreensão de EF em uma perspectiva mais ampla vai se formando.

A partir do momento que identificamos nas falas da professora indícios de que ela compreende a diferença entre a EF e a MF, seguimos a entrevista com a finalidade de compreender qual a relação que ela identifica (ou não) entre a EF e a MF. Você acha que a MF entra aí com os cálculos? E você (o sujeito) ficaria educado financeiramente a partir dos cálculos da MF? 
Não, só a partir dos cálculos não! A partir do conhecimento de você saber o que é lucro, você saber o que é juros, né? Você saber porcentagem, saber o imposto, o imposto é um exemplo bem claro, no Brasil é altíssimo, então isso também não é uma forma de orientar o aluno? Também não é Matemática Financeira? Isso não é só cálculo. Entender o que é imposto, lucro, juros, montante, capital (Professora, 2017).

Ela consegue estabelecer uma boa relação entre EF e MF, só não é aprofundada nem ampliada, mas percebe diferenças e dá indícios do que é uma e do que é outra. Destacamos também em sua fala a abordagem conjunta das duas temáticas, ela coaduna com o que defende Cunha e Laudares (2017), e nós também defendemos, que a partir do momento em que vamos ensinar MF devemos educar o aluno também para essa abordagem mais ampla, a qual entendemos como nossa concepção de EF, mesmo que em sua fala ainda pareça existir um pouco de confusão, pois a EF não corresponde apenas a mostrar o lucro, o montante, o capital e o imposto nas mercadorias, como ela diz.

Sobre as relações que podemos encontrar entre a MF e a EF, a professora destaca que tudo está correlacionado e frisa que mesmo seu pensamento de EF não apresentando uma abordagem ampla (acreditamos que ela chegou a essa conclusão durante a realização da entrevista, após perceber que podemos relacionar a EF com outras discussões/situações que não apenas a administração doméstica do dinheiro).

Eu digo a você, tem muito a pecar na Matemática Financeira, é uma coisa tão presente, tão importante e a gente não dá tanta importância, não aborda como deveria ser abordado, eu acho que a Matemática Financeira deveria ser abordada em todos os níveis, em todos os anos, um pouco em todas as séries(Professora, 2017).

Segundo a professora, o trabalho da EF durante as aulas de Matemática não é tão presente, pois não faz parte das avaliações externas. Esta fala remete à discussão que a EMC vem apresentando, que nossas aulas estão pautadas em roteiros pré-estabelecidos, construídos a partir de cobranças externas à sala de aula, com uma educação baseada em resultados quantitativos, com menor possibilidade de desenvolvimento de cidadãos críticos e conscientes frente a situações sociais, políticas, culturais, éticas, entre outras, que permeiam nossa vida em sociedade.

Sobre a EF dos bancos e a relação com a EF escolar, ela acredita que as campanhas de EF, em que você deve economizar, não são as ideais para trabalhar na escola, que devemos buscar uma alternativa mais ampla. Dessa forma ela demonstra que reconhece que os diferentes elementos da sociedade pensam e trabalham (ou abordam) a EF de acordo com as suas visões. E aí surge o questionamento: Mais ampla como, em que sentido?

Porque quando o banco faz a campanha de Educação Financeira, você vê que ele faz em benefício de si próprio, venha economizar, venha poupar, né?

ISSN 2526-2882

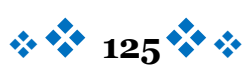


Tudo é: venha para o banco. [...] o banco vai e faz a Educação Financeira abordando só o banco, mostrando que você vai ter lucro, mas quem vai ter na realidade é o banco (Professora, 2017).

De uma forma geral a professora defende algumas ideias que estudos em EF já vêm apontando (ROSETTI; SCHIMIGUEL (2009), SILVA; POWELL (2015), GABAN; DIAS (2016), OLIVEIRA (2016), PESSOA (2016), SANTOS (2016) e SANTOS; PESSOA (2016)), a EF deve ser abordada durante toda a Educação Básica, a partir de diferentes perspectivas, pois se trata de uma temática que todos vivenciamos desde cedo, o que muda é apenas a nossa relação com as finanças, que vai se aprofundando com o passar dos anos a caminho da vida adulta. A seguir apresentamos e discutimos como as atividades de MF presentes no livro didático adotado pela professora se possibilita ou não a abordagem crítica da EF, de forma que possa potencializar a discussão em sala de aula durante as aulas de MF.

\section{Ambientes de aprendizagem presentes nas atividades de Matemática Financeira com potencial para discussão da Educação Financeira presentes no livro didático adotado pela professora}

Selecionamos as atividades do livro utilizado pela professora, aprovado pelo (PNLD, 2015). Como critério para análise das atividades presentes no capítulo referente à MF, selecionamos quarente e oito (48) atividades que compõem as seções de exercícios do capítulo de Matemática Financeira e classificamos de acordo com os potenciais ambientes de aprendizagem. Na tabela, a seguir, apresentamos uma análise quantitativa dos ambientes de aprendizagem, de acordo com as atividades analisadas.

Tabela 1 - Frequência dos ambientes de aprendizagem presentes no capítulo de MF do livro didático adotado pela professora.

\begin{tabular}{|l|c|c|}
\cline { 2 - 3 } \multicolumn{1}{c|}{} & Exercícios & Cenários para investigação \\
\hline Referências à matemática pura & 24 & 1 \\
\hline Referências à semirealidade & 19 & 1 \\
\hline Referências à realidade & 3 & 0 \\
\hline
\end{tabular}

Encontramos uma forte presença de atividades de MF situadas nos ambientes do tipo (1) e do tipo (3), coaduna com o apresentado por Skovsmose (2000) em seu estudo que busca discutir a presença e como os ambientes de aprendizagem estão organizados durante as aulas de Matemática.

Uma boa parte da educação matemática está alternando os ambientes (1) e (3). Nesse sentido, o paradigma do exercício oferece uma fundamentação assente na "tradição" da educação matemática. Muitos estudos em educação matemática têm revelado um quadro desolador sobre o que acontece na sala de aula tradicional (SKOVSMOSE, 2000, p. 14).

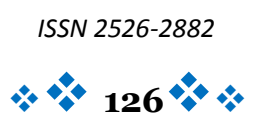


Em relação às orientações iniciais presentes no manual do livro didático utilizado pela professora sobre o trabalho com a EF, ele não apresenta de forma explícita o termo EF, mas uma discussão sobre Trabalho e Consumo, em que identificamos possíveis relações com nossa discussão de EF. Dentro do pequeno bloco de discussão apresentado, sobretudo no que é referente ao consumo, o manual apresenta a seguinte colocação, “...às vezes o consumo é apresentado como forma e objetivo de vida, transformando bens supérfluos em vitais e levando ao consumismo" (DANTE, 2013, p.227).

Nesse caso, mesmo que não seja nomeadamente uma discussão de EF, ela pode conduzir a professora por um caminho de discussão na perspectiva de um EF crítica. Além disso, apresenta uma rápida passagem sobre a composição e a qualidade de produtos, avaliação do seu impacto sobre a saúde e o meio ambiente, uma análise da razão entre o menor preço e a maior quantidade, situações de ofertas como "compre 3 e pague 2 " que nem sempre são vantajosas, pois geralmente são feitas com produtos que não apresentam muita saída, portanto, não há, muitas vezes, necessidade de comprá-los em grande quantidade, sem esquecer de quando esses produtos estão com o prazo de validade próximo do vencimento.

O manual destaca que o professor não deve deixar de discutir temas como: taxa Selic, potencial para uma discussão sobre tomada de decisão nas situações de liquidação, nas quais muitas vezes somos pegos nas armadilhas dos descontos que na verdade não são tão bons como demonstram ser.

A Atividade 1, apresentada na Figura 1, foi classificada por nós como um ambiente do tipo (4), ou seja, apresenta possibilidade de um cenário para investigação construído a partir de uma semirealidade.

A atividade está classificada de uma semirealidade, pois não representa uma situação real vivenciada por alguém, ela é construída por quem a elaborou, para possibilitar uma discussão que não seja puramente matemática, como encontramos em atividades que fazem referências à matemática pura. Acreditamos se tratar de uma atividade que envolve um cenário, pois enxergamos potencial para uma discussão sobre tomada de decisão nas situações de liquidação, nas quais muitas vezes somos pegos nas armadilhas dos descontos que na verdade não são tão bons como demonstram ser. 
Figura 1 - Atividade 1 sugerida à professora.

7. ATMDADE TOMLA Tondo decisões nas liquidações

Ana Maria quer aproveitar as liquidações para fazer compras. Observem algumas ofertas que ela encontrou.
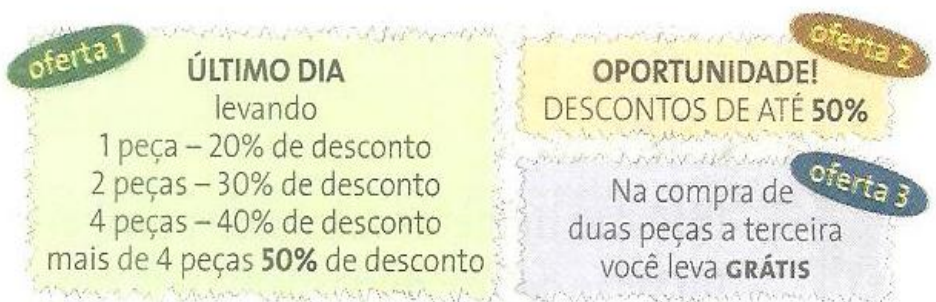

a) Qual dessas ofertas vale a pena aproveitar? Discuta com seus colegas. Oferta 1 e Oferta 3 .

b) Compare a OFERTA1 com a OFERTA 3. Em qual delas é mais vantajoso comprar 2 peças? oferta 3.

Fonte: Dante (2013, p. 15).

Na Figura 2, podemos observar a Atividade 2, proposta à professora, a qual foi classificada como pertencente ao ambiente do tipo (3), caracterizado pela presença de exercícios situados também em uma semirealidade. Classificamos a atividade dessa forma, pois ela apresenta uma situação criada pelo autor do livro didático para ilustrar um empréstimo, ou seja, não é uma situação real, e como exercício porque o objetivo da atividade é apenas a aplicação das fórmulas de juros simples e composto para identificar a melhor forma de empréstimo.

Figura 2 - Atividade 2 sugerida à professora

40. ATIVDDADE (UEMT) Uma financiadora oferece empréstimos, por um período de 4 meses, sob as seguintes condições:

$1^{\text {a) }}$ taxa de $11,4 \%$ ao mês, a juros simples;

$2^{\text {a) }}$ taxa de $10 \%$ ao mês, a juros compostos.

Marcos tomou um empréstimo de $R \$ 10000,00$, optando pela primeira condição, e Luís tomou um empréstimo de $R \$ 10000,00$, optando pela segunda condição. Quanto cada um pagou de juros?

Marcos pagou R\$ 4560,00 e Luis, R\$ 4 641,00.

Fonte: Dante (2013, p. 24).

ISSN 2526-2882 
Além das atividades, solicitamos à professora que utilizasse as orientações presentes no manual do livro didático, pois um dos nossos objetivos é inferir possíveis contribuições do manual para o trabalho com as atividades. Pode ser que uma atividade que classificamos como do ambiente tipo (3), a partir das orientações do manual e na prática de sala de aula passe a ser do tipo (4), por exemplo. Além disso, solicitamos a elaboração de um roteiro da forma como a aula foi pensada e organizada. A seguir apresentamos o momento de observação da aula da professora participante.

\section{Momento de observação}

O momento único de observação foi audiogravado e aconteceu durante a aula de MF em uma turma do $3^{\circ}$ ano do Ensino Médio. Durante a observação, apenas a professora conduziu as discussões, utilizando as atividades e orientações do manual do professor do livro didático como fio condutor da organização da aula. Apresentamos a seguir o roteiro de aula elaborado pela professora.

Figura 3 - Roteiro de aula apresentado pela professora

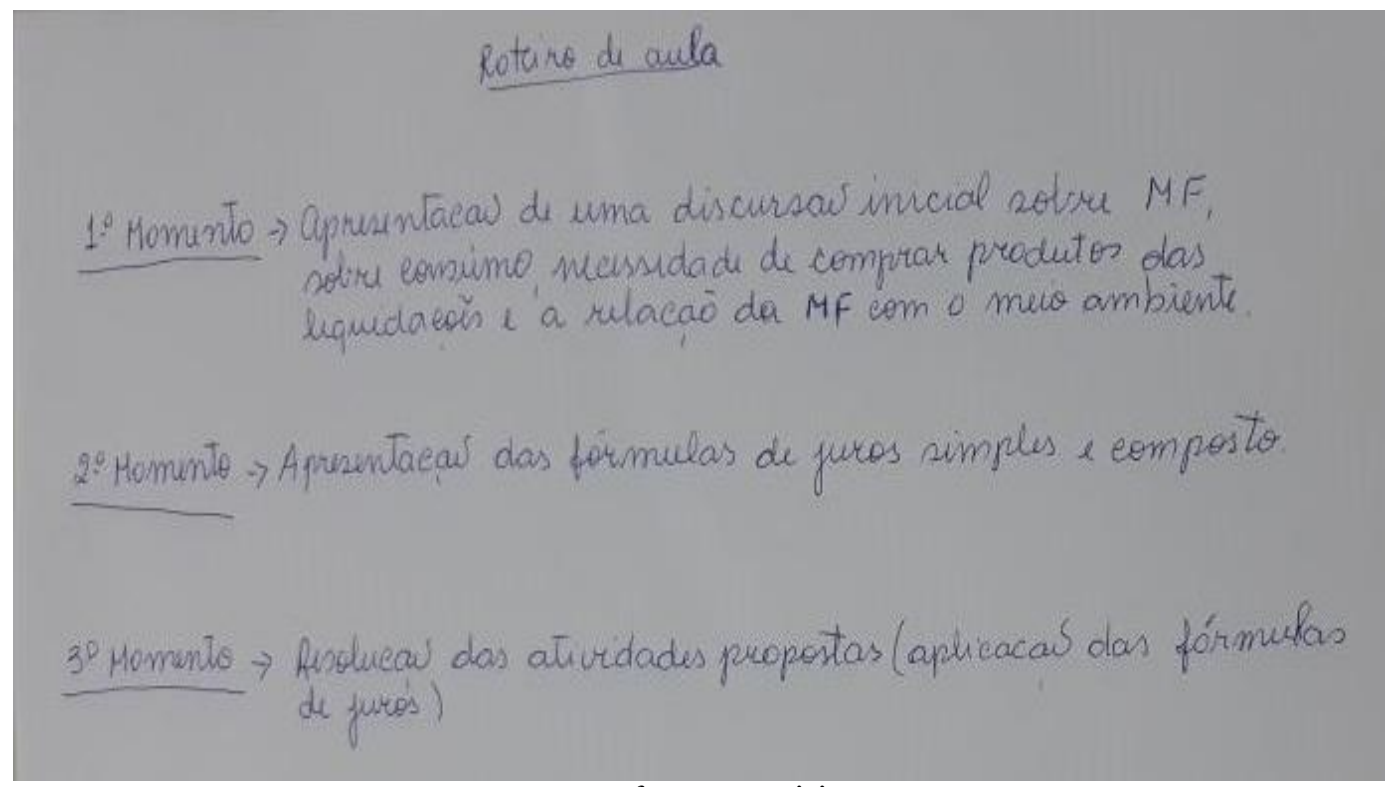

Fonte: Professora participante.

É possível identificar que a professora utiliza alguns elementos elencados nas orientações do manual do professor, presentes no bloco Trabalho e Consumo. Apresenta aos alunos os diversos aspectos que o manual apresenta sobre a temática do consumo. E destaca em sua fala uma inquietação pessoal, ela nunca pensou a MF como estando relacionada ao meio ambiente. Na verdade, ela só começou a refletir sobre essa perspectiva a partir da entrevista inicial e da rápida discussão apresentada no manual. A seguir apresentamos um ISSN 2526-2882




relato da professora sobre as situações do "compre 3 e pague 2" e das liquidações em lojas e supermercados.

Feito eu, cheguei no supermercado no dia da Black Friday, estava o povo empurrando o carrinho lotado de leite, estava por R\$ 0,99, poxa! Um litro de leite por R $\$$ o,99? O pessoal empurrando o carrinho cheio, era uma rua imensa de leite, quando eu fui olhar a validade era no outro dia, será que aquele pessoal que passou com o carrinho lotado de leite olhou que no outro dia ia vencer? [...] (Professora, 2017).

O exemplo vivenciado e apresentado pela professora coaduna com as discussões de Santos e Pessoa (2016) sobre a forma como a abordagem da EF deve acontecer, quando discutimos questões como querer versos precisar, muitas pessoas podem não precisar de uma grande quantidade de leite e não vão conseguir consumir tudo antes do prazo de validade. $\mathrm{O}$ que parece uma vantagem do ponto de vista econômico, na verdade é um prejuízo. Outra questão que podemos destacar no exemplo, é a situação do Black Friday, muito presente no mundo do consumo hoje e que seria exatamente um exemplo do que Bauman (2008) trata sobre o consumismo, quando compramos por impulso, quando compramos mais do que realmente precisamos. Ainda na perspectiva de apresentar exemplos que retratam as situações sugeridas pelas orientações do manual, a professora destaca:

[...] produtos fabricados na china, com preço mais em conta, hoje em dia tá menos, mas teve uma época que o consumo desses produtos era muito grande, as bijuterias vendiam demais, vendiam bastante, porque eram baratas, todo mundo comprava, depois foi descoberto que a composição do material tinha chumbo e prejudicava a saúde. Será que o custo-benefício de comprar aquele objeto barato vale a pena? Se ele além de prejudicar a saúde, prejudica o meio ambiente? (Professora, 2017).

Como afirmado anteriormente, a partir da análise das atividades, selecionamos duas, para que sejam parte da aula de MF da professora participante, utilizamos como critério de seleção, atividades nas quais enxergamos possibilidades de uma reflexão sobre EF, de forma que possamos identificar a relação com a MF e como ela é construída pela professora.

É possível perceber que a MF é utilizada em alguns momentos pela professora como sinônimo da EF, pois ela apresenta exemplos de situações que podem gerar uma discussão crítica da EF, mas que da forma com ela apresenta não fica tão claro para nós qual a sua real compreensão do que é a MF e a sua relação com a EF. Se levarmos em consideração as orientações do manual do professor, percebemos que elas podem ter contribuído para essa incompreensão da professora, já que o próprio manual não apresenta como sendo uma abordagem de EF e não fala em relações entre a MF e a EF, podendo ser esse o motivo da falta de compreensão clara pela professora sobre esta relação. 
Embora identifiquemos algumas incompreensões em sua fala, podemos destacar que a professora, de certa forma, entendeu que na EF deve haver um olhar crítico para questões sociais, quando se refere às situações de promoções, quando aborda o caso dos produtos chineses, quando trata da relação custo-benefício, ou seja, são discussões que possuem um alto grau de potencialidade para uma abordagem crítica e reflexiva das questões financeiras que permeiam nossa vida em sociedade e assim podermos estar caminhando para um cenário em que a EF crítica que defendemos seja abordada com propriedade por professores e alunos.

Em relação às atividades sugeridas à professora, elas representaram o foco do roteiro apresentado, ela organiza discussões iniciais sobre EF, consumo, necessidade das compras e por fim a relação com o meio ambiente. Em seguida apresenta as fórmulas de juros simples e compostos seguidas da resolução das atividades como exercícios pelos alunos, como forma de aplicação dos conceitos e fórmulas de juros simples e compostos (conteúdos abordados nas atividades).

Concluímos que não existe uma relação direta na aula entre os conteúdos de MF e $\mathrm{EF}$, ambas foram apresentadas em diferentes momentos, é como se os elementos e as situações financeiras da EF fossem usados apenas como forma de introdução aos conteúdos da MF. Mas como destacamos anteriormente, a professora buscou apresentar algumas discussões que julgamos importantes, tendo em vista que se pensarmos bem, ela poderia ter iniciado a aula apenas com a exposição dos conceitos e fórmulas da MF, o que realmente faltou foi a construção de uma relação mais explícita e direta.

Em relação à classificação das atividades de acordo com os ambientes propostos por Skovsmose (2000), buscamos agora verificar como aconteceu na prática da sala de aula a abordagem desses ambientes. Comparando a nossa classificação inicial das duas atividades construímos o Quadro 3, a seguir, em que podemos observar nossa classificação prévia e nossa classificação a partir da prática da professora.

Quadro 3- Comparação dos ambientes de aprendizagem das atividades antes e depois da prática de sala de aula.

\begin{tabular}{|l|c|l|}
\hline & Classificação inicial & \multicolumn{1}{c|}{ Classificação a partir da prática } \\
\hline Atividade 1 & Cenários + Semirealidade & Exercício + Semirealidade \\
\hline Atividade 2 & Exercício + Semirealidade & Exercício + Semirealidade \\
\hline
\end{tabular}
Fonte: Os autores

Como podemos observar, a Atividade 1, que classificamos previamente como sendo do tipo (4), cenários em uma semirealidade, a partir da observação em sala, passa a ser classificado no ambiente do tipo (3), pois a professora a utilizou apenas para aplicação das fórmulas da MF. Já a Atividade 2, previamente classificada como pertencente ao ambiente do tipo (3), por apresentar exercícios em uma semirealidade, continua sendo do mesmo ISSN 2526-2882

$$
* 131 *
$$


ambiente durante a prática da professora, já que ela não modificou a proposta da atividade. Concluímos, nesse caso, que não basta as atividades de MF apresentarem potenciais para uma discussão de elementos da EF, como a Atividade 1, por exemplo, é preciso que os professores recebam uma formação adequada nessa perspectiva e que principalmente, as orientações presentes no manual do professor, que devem orientar o trabalho com as atividades, estejam realmente alinhados com uma perspectiva mais crítica de formação dos sujeitos, e não apenas prepará-los para decidir qual a situação mais vantajosa do ponto de vista econômico, apenas.

Destacamos também o papel importante da professora, que apesar da sua incompreensão pessoal sobre o que trata a MF e a EF e consequentemente suas relações diretas, possibilitou elementos que poderiam permitir uma gama de discussões pertinentes, apesar das fracas orientações do manual do professor e da falta de formação a respeito da temática.

\section{Considerações}

A professora participante do nosso estudo teve pouco contato com a temática durante sua formação inicial. Ela relaciona MF à aplicação de conhecimentos matemáticos à vida cotidiana dos alunos e com isto destaca a sua importância na formação escolar. Ela discute que não devemos trabalhar somente a partir de fórmulas durante as aulas, segundo ela, essa forma de abordagem está sendo superada aos poucos no ensino da Matemática, consequentemente na MF, quando trazemos situações do dia a dia dos alunos para a sala de aula. Sobre a concepção de EF, a professora reconhece que possui a noção de EF apresentada pela mídia, muito relacionada a situações domésticas e a partir dos nossos questionamentos e inquietações no momento da entrevista, ela percebe que podemos ir muito além dessa perspectiva limitada, em direção a uma EF crítica. Apesar de restrita, ela apresenta indícios do que defendemos como abordagem para $\mathrm{EF}$, pois destaca que não corresponde apenas ao trabalho com dinheiro e sua variação no tempo, nem apenas restrita a conceitos como juros, porcentagem ou aspectos técnicos da MF. Destacamos que ela consegue identificar uma boa relação entre EF e MF, só não é aprofundada, nem ampliada.

A análise das atividades presentes no capítulo de MF do livro didático adotado pela escola, a partir dos ambientes de aprendizagem estabelecidos pela EMC, coaduna com os resultados de Gaban e Dias (2016) e a análise de Skovsmose (2000) sobre o ensino de Matemática, as atividades, em sua maioria, estão situadas no paradigma do exercício com referência à matemática pura ou a semirrealidade. As atividades de MF por si só não possibilitam uma discussão mais elaborada de EF se a professora se restringir apenas ao potencial das atividades. Defendemos uma mudança de postura por parte dos organizadores 
dos livros didáticos nas estruturas das atividades, não só de MF, como de todo o ensino de Matemática.

As orientações presentes no manual do professor não apresentam de forma explícita o termo EF, apresenta um bloco de discussão sobre Trabalho e Consumo, mas que podemos identificar elementos que fazem parte das discussões de EF, como: composição e qualidade dos produtos, impacto no meio ambiente, necessidade real de compra dos produtos em situações do tipo "compre 3 e pague 2". Podemos identificar a presença desses elementos, defendidos nas orientações do manual, na prática da professora, ela utilizou exemplos de algumas das situações como forma de introduzir o conteúdo de MF.

Como foi solicitado durante a entrevista inicial, a professora organizou um roteiro para um momento de aula de $\mathrm{MF}$, o qual observamos que ela seguiu. O roteiro da professora foi dividido em três momentos, de início ela apresenta ideias gerais com diversas situações financeiras, em seguida existe a exposição das tradicionais fórmulas de juros simples e compostos e as atividades sugeridas à professora serviram apenas como aplicação prática das fórmulas expostas anteriormente.

No que diz respeito à relação estabelecida pela professora da MF com a EF durante o momento de observação da aula, concluímos que ela não abordou de forma direta a relação, mas em momentos diferentes. É como se os elementos e as situações financeiras da EF fossem usados apenas como forma de introdução aos conteúdos da MF, mesmo não sendo a forma de abordagem crítica da EF que defendemos, enxergamos como algo positivo, se pensarmos que a professora poderia ter iniciado a aula apenas com a exposição dos conceitos e fórmulas da MF, o que realmente faltou foi a construção de uma relação mais explícita e direta, que pode ser motivada por falta de compreensão da professora ou por influência das orientações do manual, já que ele não estabelece a relação.

Em relação à classificação das atividades a partir dos ambientes propostos por Skovsmose (2000), e à prática da sala de aula da professora, observamos uma mudança quando comparamos a nossa classificação inicial das duas atividades e nossa classificação a partir da prática da professora. A Atividade 1, que classificamos previamente como sendo do tipo (4), cenários em uma semirealidade, passa a ser do ambiente do tipo (3), já que a professora a utilizou apenas como exemplo de aplicação de fórmulas. Já a Atividade 2, classificada inicialmente como pertencente ao ambiente do tipo (3), por apresentar exercícios em uma semirealidade, é classificada no mesmo ambiente na prática da professora.

De forma geral, concluímos, após a realização do estudo, que o trabalho com a EF envolve um conjunto de elementos que vão além da prática da professora. No início ela apresentou uma certa incompreensão sobre MF e EF e, em consequência, sobre relação entre as duas áreas, a partir dos nossos questionamentos e reflexões durante a entrevista, ISSN 2526-2882 
reconhece que sua visão de EF é de certa forma limitada e enxerga as possibilidades de uma abordagem mais ampla da EF. Em relação às atividades, destacamos que não é suficiente as atividades de MF apresentarem potenciais para uma discussão de elementos da EF, é preciso que tenhamos uma formação de professores em uma perspectiva crítica da EF escolar e que principalmente, as orientações presentes no manual do professor, que devem orientar o trabalho com as atividades, estejam realmente alinhados com uma perspectiva mais crítica de formação dos sujeitos e que não abordemos as situações financeiras apenas na perspectiva de identificar a melhor forma de pagamento, ou em qual situação hipotética de empréstimo vamos pagar menos juros, deixando de lados as questões sociais, políticas, culturais, éticas e ambientais que podemos discutir.

\section{Referências}

BAUMAN, Zigmunt. Vida para consumo: a transformação das pessoas em mercadoria. Rio de Janeiro: Zahar Ed., 2008.

BENNEMANN, Marcio; ALlEVATO, Norma. Educação Matemática Crítica. Revista de Produção Discente em Educação Matemática, São Paulo, v.1, n.1, p. 103-112, 2011.

Disponível em: $<$ https://revistas.pucsp.br/index.php/pdemat/article/view/9226/6845 > Acesso em 30 ago. 2017.

BRASIL. Parâmetros Curriculares Nacionais. Brasília, 1997.

BRASIL. BRASIL: Implementando a Estratégia Nacional de Educação Financeira. 2010. <http://www.bcb.gov.br/pre/pef/port/Estrategia_Nacional_Educacao_Financeira _ENEF.pdf. > Acesso em: 24 de mai. 2018.

BRASIL. Guia de livros didáticos: PNLD 2015: matemática: ensino médio. Brasília: Ministério da Educação, Secretaria de Educação Básica, 2014.

CAMPOS, Marcelo. Educação Financeira na Matemática do Ensino Fundamental: Uma análise da produção de significados. Dissertação de Mestrado em Educação Matemática. Universidade Federal de Juiz de Fora- UFJF, Juiz de Fora, 2013.

COUTINHO, Cileda; TEIXEIRA, James. Letramento Financeiro: Um Diagnóstico de Saberes Docentes. REVEMAT- Revista Eletrônica de Educação Matemática, Florianópolis, v.10, n.2, p. 1-22, 2015. Disponível em: < http://dx.doi.org/10.5007/1981-1322.2015v10n2p1> Acesso em: 08 ago. 2017.

CUNHA, Clístenes. LAUDARES, João. Resolução de Problemas na Matemática Financeira para Tratamento de Questões da Educação Financeira no ISSN 2526-2882 
Ensino Médio. Bolema - Boletim de Educação Matemática, Rio Claro (SP), v. 31, n. 58, p. 659-678, ago. 2017. Disponível em: <http://www.scielo.br/scielo.php?script=sci_arttext\&pid=So103636X2017000200659\&lng=pt\&tlng=pt > Acesso em: 27 jan. 2018.

DANTE, Luiz. Matemática Contexto \& Aplicações. São Paulo: Ática, 2. ed., 2013.

GABAN, Artur; DIAS, David. Educação Financeira e o Livro Didático de Matemática: Uma análise dos Livros aprovados no PNLD 2015. Anais do XII Encontro Nacional de Educação Matemática- XII ENEM, São Paulo, 2016.

LIMA, Cristiane; SÁ, Ilydio. Matemática Financeira no Ensino Fundamental. Revista Teccen - Universidade Severino Sombra, v. 3, n. 1, abr. 2010.

MUNIZ, Ivail. Educação Financeira e a sala de aula de Matemática: conexões entre a pesquisa acadêmica e a prática docente. Anais do XII Encontro Nacional de Educação Matemática- XII ENEM, São Paulo, 2016.

OLIVEIRA, Anaelize. Educação Financeira: como está sendo abordada nos $4^{\circ}$ e $5^{0}$ anos do Ensino Fundamental? Anais do XX Encontro Brasileiro de Estudantes de Pós-Graduação em Educação Matemática- XX EBRAPEM. Curitiba, 2016.

PESSOA, Cristiane. Educação Financeira: O que tem sido produzido em mestrados e doutorados defendidos entre 2013 e 2016 no Brasil? In: CARVALHÊDO, J.; CARValho, M. V.; ARAuJO, F. (orgs.) Produção de conhecimentos na Pósgraduação em educação no nordeste do Brasil: realidades e possibilidades. Teresina: EDUPI, 2016.

ROSETTI, Hélio; SCHIMIGUEL, Juliano. Educação matemática financeira: conhecimentos financeiros para a cidadania e inclusão. InterScience Place, v. 2, p. 1-13, 2009.

SANTOS, Jéssica; MIRANDA, Fabíola. Educação Matemática Crítica e Conexões. Anais do XII Encontro Nacional de Educação Matemática- XII ENEM, São Paulo, 2016.

SANTOS, Thalita; PESSOA, Cristiane. Educação financeira na perspectiva da educação matemática crítica: uma reflexão teórica à luz dos ambientes de aprendizagem de Ole Skovsmose. BoEM- Boletim online de Educação Matemática, Joinville, v.4, n.7, p. 23-45, ago./dez. 2016. Disponível em: < http://www.revistas.udesc.br/index.php/boem/article/view/8540> Acesso em: 28 jul. 2017.

SANTOS, Thalita. Educação Financeira em livros didáticos de matemática dos anos iniciais do ensino fundamental: quais as atividades sugeridas nos livros dos alunos e as orientações presentes nos manuais dos ISSN 2526-2882 
professores? Anais do XX Encontro Brasileiro de Estudantes de Pós-Graduação em Educação Matemática- XX EBRAPEM. Curitiba, 2016.

SILVA, Amarildo; POWELL, Arthur. Um Programa de Educação Financeira para a Matemática Escolar da Educação Básica. Anais do XI Encontro Nacional de Educação Matemática- XI ENEM, Curitiba, 2013.

SILVA, Amarildo; POWELL, Arthur. Educação Financeira na Escola: A perspectiva da Organização para Cooperação e Desenvolvimento Econômico. Juiz de Fora, 2015. Disponível em: <http://dx.doi.org/10.4322/gepem.2015.024> Acesso em: 07 dez. 2016.

SILVA, Inglid. Educação Financeira e Educação Matemática Crítica na escola: articulando conhecimentos no Ensino Médio. Anais do XIX Encontro Brasileiro de Estudantes de Pós-Graduação em Educação Matemática- XIX EBRAPEM. Juiz de Fora, 2015.

SKOVSMOSE, Ole. Cenários para investigação. BOLEMA - Boletim de Educação Matemática, Rio Claro, n. 14, p. 66-91, 2000. Disponível em: < http://www.pucrs.br/famat/viali/tic_literatura/metodologia/Skovsmose_Cenarios _Invest.pdf > Acesso em 22 ago. 2017.

. Um convite à Educação Matemática Crítica. São Paulo: Papirus, 2014.

TEIXEIRA, James. Um estudo diagnóstico sobre a percepção da relação entre educação financeira e matemática financeira. Tese de Doutorado em Educação Matemática. Pontifica Universidade Católica de São Paulo- PUCSP, São Paulo, 2015 .

\section{Bibliografia Resumida}

Danilo Pontual de Melo - Licenciado em Matemática pela Universidade Federal de Pernambuco (UFPE). Mestrando do Programa de Pós-Graduação em Educação Matemática e Tecnológica (EDUMATEC) pela Universidade Federal de Pernambuco (UFPE). Membro do Grupo de Estudos em Desenvolvimento e Aprendizagem Matemática GREDAM/UFPE.

link lattes: http://lattes.cnpq.br/6820011450803149

e-mail: danilopontualufpe@gmail.com 
Cristiane Azevêdo dos Santos Pessoa, Doutora em Educação pela Universidade Federal de Pernambuco (UFPE). Professora Associada 1 do Departamento de Métodos e Técnicas de Ensino e da Pós-Graduação em Educação Matemática e Tecnológica da UFPE, Recife, Pernambuco, Brasil. Líder do Grupo de Estudos em Desenvolvimento e Aprendizagem da Matemática na Educação Básica - GREDAM/UFPE.

Link Lattes: http://lattes.cnpq.br/3021252548409195

e-mail: cristianepessoa74@gmail.com 